\section{TITULO DE ANTICORPOS EM CAVALOS IMUNIZADOS COM VACINA CONTRA INFLUENZA EQÜINA}

DALVA ASSUNCAOO PORTARI MANCINI

Pesquisadora Cientifica III Instituto Butantan

ELAINE APARECIDA GERALDES

Bióloga - Estagiária Instituto Butantan

JOSE RICARDO PINTO

Pesquisador Cientifico I Instituto Butantan

MANCINI, D.A.P.; GERALDES, E.A.; PINTO, J.R. Tf́tulo de anticorpos em cavalos imunizados com vacina contra influenza eqüina. Braz J. veh Res. anim. Sci., São Paulo, v.28, n.2, p.171-7, 1991.

RESUMO: Vacinas contra influenza equina bivalentes ( $A / E q_{1}$ e $A / E q_{2}$ ) inativadas, sem e/ou com adjuvante de hidróxido de alumínio, produzidas no Instituto Butantan, foram comparadas quanto a sua capacidade de induz ir a produção de anticorpos especificos, através dos testes de inibição da hemaglutinaçăo (IH) e de nemólise radial simples (HRS), em dois lotes de potros. Pela análise de títulos de anticorpos no soro, a partir de avaliaçōes semenais, verificou-se que ambos os tipos de vacina apresentaram imunogenicidade. Ao prazo de un mès da vacinaçăo observou-se que a imunizaçăo com vacina adicionada de adjuvante, comparada à imunizaçāo com vacina simples, resultou em respostas de anticorpos com títulos mais elevados tanto para IH como HRS, avaliadas frente às duas cepas virais.

UNTTERMOS: Influenza, equinos; Vacinas; Anticorpos

\section{INTRODUÇAOO}

Surtos epidémicos da influenza eqüina tèm ocorrido frequentemente no mundo, ocasionando altos indices de morbidade entre os animais afetados 2,22 Apesar do prognóstico benigno da enfermidade, podem ocorrer complicaçóes tais como infecções secundárias, agravando a doença 2,10. o vírus da influenza eqüina A/Eq, foi inicialmente isolado en Praga, Tchecoslovéquia, em 1956, surgindo nos Estados Linidos, somente en 1963. Neste mesmo ano ocorreu en Miami, Flórida, un surto do vírus influenza $A / E q_{2}$ que causou $80 x$ das mortes entre os animais da regibo. Os isolamentos das cepas $A / E q_{1}$, ass in como a $A / E q_{2}$ do vírus influenza serviram de fonte para a produçăo de vacina bivalente "fluvac", após exaustivos estudos realizados pelo Departamento de Ciéncias Veterinárias da Universidade de Kentucky, USA. Esta vacina, após sucessivos testes, foi liberada para uso en 1965. Depois de mais de 20 anos de seu emprego, năo houve al teração das cepas constituintes ${ }^{13}$. autros estudos realizados com vírus da influenza equina demonstraram bons resultados na obtençăo de imunógenos, que for am capazes de induzir ammento significativo no nivel de anticorpos protetores em enimais vacinados $1,7,9,14,20,23$. Principalmente, considerando-se que as cepas do tipo a do vírus influenza apresentam um antígeno tipo especifico comm entre elas, o que foi observado através de reaçōes sorológicas ${ }^{16}$.

No Brasil, O isolamento das cepas $\mathrm{A} / \mathrm{Eq}_{1}$ e $\mathrm{A} / \mathrm{Eq}_{2}$, foi realizado após o surto de influenza em equinos no Estado de São Paulo, em 1963 e $19699^{17}$ e Rio de Janeiro, em 1969, 1976 e 1985 3,4,6.

Novas informações sobre as propriedades antigênicas do vírus influenza tèm contribuido, de forma efetiva, para o esclarecimento das cepas variantes incidentes, e concomitantemente no planejamento das medidas de controle da infecçăo ${ }^{11}$. Assim, a vacinaçăo tem sido a mais eficaz soluçăo contra a infecça viral, principalmente en locais de alta morbidade do vírus 1,14 . Deve-se considerar, tambén, que pesquisas realizadas após perf́odos epizoóticos da influenza eqüina demonstraram aumento expressivo nos titulos de anticorpos contra influenza, em an imais que haviam sido préviamente vacinados ${ }^{7}$.

O uso de adjuvantes associados a vacina contra influenza tem sido relatado, demonstrando um aumento na produçăo de anticorpos. Substancias como alginato de sódio, adjuvante de Freund, óleo mineral, e sistemas como óxido de alumínio, hidróxido de alumínio, fosfatos de cálcio e alumínio, tém sido empregados como potencializadores de antigenos $8,12,18$. Todavia, o emprego de adjuvantes pode induz ir a formação de inflamação e o desenvolvimento de tunores no local da aplicaçăo. Por isso, deve-se equacionar a utilização destas substancias, considerando-se o título de anticorpos alcançados frente ao grau de agressão induzida ao animal.

Tendo em vista que no Brasil, várias ocorréncias da influenza eqüina têm sido relatadas $4,6,11,14$, e não havendo dados atuais sobre a resposta de soroconversão de animais imunizados e, ainda, que as 
Título de anticorpos en cavalos imunizados com vacina contra influenza equina.

vacinas dispontveis são normalmente importadas, é que se procurou, no presente trabalho, avaliar una vacina bivalente contra influenza equina, preparada experimentalmente em nossos laboratórios do Serviço de Virologia, no Instituto Butantan, com as cepas A/Eq, $\mathrm{A} / \mathrm{Eq}_{2}$ do vírus influenza, isoladas no Instituto Adolfo Lutz. Analisou-se a influência do hidróxido de alumínio como adjuvante $e$ a persistência de anticorpos nos animais vacinados, durante aproximadamente cinqüenta dias.

\section{MATERLAL E MÉTODO}

1- Vinus

Os tipos $\mathrm{A} / \mathrm{Eq}_{1} / \mathrm{SP} / 1 / 56\left(\mathrm{H}_{7} \mathrm{~N}_{7}\right)$ e $\mathrm{A} / \mathrm{Eq}_{2} / \mathrm{SP} / \mathrm{M} / 85$ $\left(\mathrm{H}_{3} \mathrm{~N}_{8}\right)$ do virus de influenza eqüina* foram cultivados em ovos embrionados de galinha (Specific Pathogen Free), de 11 dias, através de passagens sucessivas.

2 - Preparo da Vacina

A vacina cortra gripe eqüina foi preparada experimentalmente com os antigenos do virus da influenza eqüina $A / E q_{1}\left(H_{7} N_{7}\right)$ e $A / E q_{2} \quad\left(H_{3} N_{8}\right)$, opedecendo aos padrōes da Organização Mundial da Saúde 15 para a produção de vacina contra gripe de uso humano, e compreendendo, basicamente, as seguintes etapas:

a) cultivo do vírus influenza em células da cavidade alantóide de ovos embrionados da gal inha (S P F);

b) colheita do virus após incubação a $36{ }^{\circ} \mathrm{C}$ por $40 \mathrm{~h}$;

c) concentração do vírus em ultracentrífuga Sharples (50.000 rpm) com fluxo contínuo;

d) inativaçao viral através do formol a 1:2.000. Os concentrados virais $\left(A / E q_{1}\right.$ e $\left.A / E q_{2}\right)$, diluidos em solução tampão fosfato até a concentração antigènica final de 100 u.h., geraram a vacina bivalente simples (V.S.) que, acrescida de hidróxido de aluminio $\left(\mathrm{Al}(\mathrm{OH})_{3}\right)$ a $30 \%$, resultou na vacina bivalente com adjuvante (V.A.). Como conservante foi utilizado o thimerosal a 1:10.000. Provas de potência e de segurança foram realizadas no decorrer do processamento das vacinas ${ }^{15}$.

* Isolados no Instituto Adolfo Lutz de São Paulo e gentilmente cedidos pela Dra. Sueko Iakimoto.

\section{3 - Animais Utilizados}

Cavalos (potros) com idade média de 2,5 anos, pertencentes ao plantel da Fazenda såo Joaquim do Instituto Butantan, foram separados em 3 lotes:

Lote A - 14 animais, imunizados com a vacina simples (V.S.).

Lote B - 15 animais, imunizados com a vacina adicinada de adjuvante (V.A.).

Lote C 05 animais controle, não vacinados.

\section{4 - Imunizaçāo e Sangrias}

As imunizaçōes, constando de duas doses de vacina de $3,0 \mathrm{ml}$ cada una, foram realizadas com intervalo de duas semanas. Os animais foram sangrados antes das imunizações e 7,14,21,28,35 e 42 dias após a primeira imunizaçāo.

\section{5 - Testes Sorológicos}

o teor de anticorpos nos soros dos eqüinos foi avaliado através dos métodos de inibição da hemaglut inaçāo e hemól ise radial simples.

\subsection{Inibição da Hemaglut inaçåo (IH)}

Foi utilizado o método de Takatsy ${ }^{21}$, que se baseia na inibição da ação hemaglutinante dos vírus, através de anticorpos especificos. Amostras de soro foram inativadas a $56{ }^{\circ} \mathrm{C}$ e tratadas com Caolim a $20 \%$ en solução tampão fosfato (PBS), para remoção de anticorpos inespecificos. Destes tratados foram feitas diluiçōes em duplicata, seriadas, em microplacas de fundo em "V". Antígeno do vírus influenza, cultivado em ovos embrionados, contendo 4 unidades hemaglutinantes, fo $i$ adicionado às cavidades. Após 1 hora de reação à temperatura ambiente, acrescentaramse hemácias de galo a $0,5 \%$. Ao fim de 30 min., procedeu-se à leitura, considerando-se como título do anticorpo, a recíproca da última diluição que induziu inibição da hemaglutinação. Os soros que apresentaram títulos de anticorpos iguais ou superiores a 1/20, for am considerados positivos. 
Título de anticorpos en cavalos imunizados can vacina contra influenza eqüina.

\subsection{Henolise Radial Simples (HRS)}

Foi utilizado o metodo de schilo et al. ${ }^{19}$, que se fundementa na lise das hemácias de galo, sensibilizadas con vírus e mediada pelo complemento (soro fresco de cobaia), quando na presenca de anticorpos especfficos. Placas de poliestireno $(12,5 \times$ $8,5 \mathrm{~cm}$ ) foram preparadas com $20 \mathrm{ml}$ de agarose a $1 \%$, fundida e resfriada a $43{ }^{\circ} \mathrm{C}$, adicionada de $4 \mathrm{ml}$ de antigeno de vírus influenza (50 unidades hemag(utinantes), previamente absorvido com $4 \mathrm{ml}$ de suspensto a $10 x$ de hemácias de galo, em soluçio de D.G.V. (dextrose 1 \%, gelatina 0,06 ox e veronal 0,03 a), sob refrigeraço por $30 \mathrm{~min}$. En sequida, adicionou-se agarose, $1 \mathrm{ml}$ de complemento (soro fresco de cobaio) com 125 unidades - $\mathrm{CH}_{50}$. Apos incubaçlo de $30 \mathrm{~min}$. temperatura ambiente, foram feitas perfuraçzes de $3 \mathrm{~mm}$ de diametro na agarose, ds quais se adicionaran os soros dos animais imunizados, previemente inativados a $56^{\circ} \mathrm{C} / 30 \mathrm{~min}$. Ao completar 18 $h$ de incubaçbo em cânara úmida, foi realizada a leitura do diánetro das áreas de henblise. Estas medidas forneceran uma avaliacso indireta da concentracto de anticorpos no soro, sendo considerados reaç̇o positiva, os valores iguais ou superiores a 2,0 mim.

\section{RESULTADOS**}

As Fig. 1,2,3 e 4 mostram teor de anticorpos nos soros dos equinos imunizados com as vacinas simples (V.S.) e com adjuvante (V.A.), avaliadas através dos testes IH $\mathrm{CHRS.}$

Na Fig. 1 encontram-se os resultados dos soros dos animais que apresentaran titulos de anticorpos inibidores da hemaglutinacto iguais ou superiores a 1/20, valores considerados satisfatórios frente a imunizaço con antígeno influenza $A / E q_{1}$ com $e$ sem adjuvante.

Os animais vacinados com antigeno influenza associado ou nao ao adjuvante, que apresentaram títulos de anticorpos inibidores do hemaglutinaço iguais ou superiores a 1/20, para o vírus $A / E q_{1}$, encontram-se na Fig. 2.

As Fig. 3 e 4 apresentan as médias dos títulos de anticorpos verificados en diânetro dos halos de hemblise para os antígenos $A / E q_{1}$ e $A / E q_{2}$ com e sem adjuvante, respectivamente, detectados nos soros dos potros vacinados, com valores iguais ou superiores a $2,0 \mathrm{~mm}$.

\footnotetext{
- Aos resultados foi aplicado o teste $t$ de Student. Na elaboraça dos gráficos foi utilizado o Harvard Graphics Program em um computador PC XT.
}

Os cinco animais controle, nāo vacinados, nto apresentarem tftulos de anticorpos detectóveis quer pelo metodo de inibicto da hemaglutinaço ou pelo metodo de henolise radial simples.

Comparando-se os numeros de enimais qu apresenteran positividade frente aos entigenos influenze $A / E q_{1} \subset A / E q_{2}$, com e sem adjuvente, observase que vacina adjuvantada apresentou immogenicidade significantenente superior vacina sem adjuvante ( $P$ < 0,01 , cepa $A / E q_{1} \in P<0,05$, cepa $A / E q_{2}$ ).

Na análise do soro dos animais que apresentaram medias de títulos de enticorpos verificados pela hemblise radial simples, observa-se, tanbem, sienificencia para vacina com edjuvente $(P<0,05$, para ambas as cepas $A / E q_{1}$ e $A / E q_{2}$ ).

\section{DISCUSSTOO E CONCLUSOES}

A escolha de animais jovens, con idade media de 2,5 anos para avaliaço da imunizaço contra a influenza eqüina, prende-se ao fato deles apresentarem maior indice prévio de soronegativos, devido menor freqüencia de exposiçlo infecclo, contrarienente ao que ocorre com animais adultos 11 .

A investigaço sorologica oferece importante suporte so monitoramento de una vacinaçzo contra determinada infecclo, por ́m, depende de complementos cono abservaço do quadro clínico e do isolamento do agente etiologico, quando se trata do diagnostico de uma infecço natural. Os testes sorológicos, como inibicto da hemaglut inaçto e hemólise radial simples, sto os mais indicados para avaliaça imunológica da vacinaço contra a influenza equina, cuja correlaço entre si é considerada satisfatória e comprovadora dos resultados 23

Mas Fig. 1 e 2 pode-se observar, pelo método da

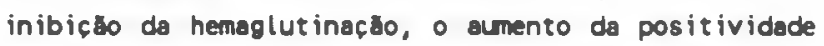
- imunizaço a partir da segunda sangria, com aumento significativo nas subseqüentes sangrias dos animais que receberam a vacina associada ao hidróxido de alumínio. Nestas figuras observa-se, tembem, que entígeno $A / E q_{1}$ apresentou menor capacidade imunogénica e menor persisténcia de anticorpos, quando comparado so antigeno $A / E q_{2}$.

As curvas de niveis de enticorpos, detectadas pelo metodo da hemólise radial simples, indicem aumento significativo jó na terceira sengria, permanecendo até a 51 sangria, quando entlo se inicia o declínio destes niveis.

Da mesma forme que se observa, atraves dos resultados obtidos pelo método de inibiçăo da hemaglutinaço, maior capacidade imunogènica para a vacina adjuvantada, verificam-se, também, resultados 
Título de anticorpos em cavalos imunizados com vacina contra influenza eqüina.

equivalentes obtidos pelo método da hemolise radial simples. E importante destacar que este método permite avaliar os títulos de anticorpos de maneira mais sensível do que o método da inibição da hemaglut inação 19. Estes dados estão de acordo com as observações feitas por wood et al. 23 que, trabathando com pône is imunizados com vacina contra influenza, observaram maior positividade do soro analisado pelo método da nemólise radial simples. CuNHA et al. 5 também verificaram boa potencializaça do antígeno na presença do hidróxido de alumínio, na resposta imunológica de cavalos vacinados contra influenza equina, por diferentes vias de inoculação.

outro fato relacionado com a eficiência do adjuvante é que, dentre os 15 potros imunizados com vacina contra influenza eqüina adjuvantada, apenas dois não apresentaram resposta de anticorpos inibidores da hemaglut inação para os antígenos $\mathrm{A} / \mathrm{Eq}_{1} \mathrm{e}$ $A / E q_{2}$, embora todos fossem soropositivos ao método da hemólise radial simples.

Portanto, podemos considerar, através de nossas análises e de outros pesquisadores 5 , que o uso de adjuvante do tipo aquoso $\mathrm{Al}(\mathrm{OH})_{3}$ em associação à vacina contra influenza equina é válido, face a sua ação imunomodeladora. Somando-se $a$ isto, é importante caracterizar que, pelas observaçōes clínicas realizadas semanalmente nos animais de nosso experimento, não se constatou qualquer tipo de alteração que pudesse eventualmente ocorrer pelo uso do hidróxido de alumínio.

Devido ao declínio de títulos de anticorpos verificados durante a investigação, é licito crer que a persisténcia de anticorpos contra a influenza eqüina é curta, como havia sido observado por nós em trabalho anterior 11.

Comprovada a imunogenicidade das cepas $A / E q_{1}$ e $A / E q_{2}$ do vírus influenza, avaliadas neste estudo, podemos concluir que elas estariam adequadas para compor a elaboração de un imunógeno com características necessárias para oferecer proteção aos equinos susceptíveis à infecçāo. Devemos ressaltar que a autosuficiência de produção desse imunobiológico traria vantagens à eqüinocultura brasileira, no aspecto de poder diminuir a demanda de sua importaça e, conseqüentemente, a redução de custos neste particular.

Considerando a necessidade de se estabelecer o prazo entre a imunização inicial e a dose reforço, á pesquisa prossegue, objetivando investigar a persistencia de anticorpos nos animais vacinacos contra influenza eqüina, durante o período de um ano. Ass im como se pretende estudar, também, o efeito de outros adjuvantes na resposta imune da vacina contra influenza equina.

\section{AGRADECIMENTOS}

AO FEDIB (Fundo Especial de Despesas do instituto Butantan), pela bolsa de estudo concedida, através da aprovaçăo deste trabalho, à estagíría Elaine A. Geraldes.

A Dra. Edda de Rizzo, Diretora do Serviço de Virologia do Instituto Butantan, pela colaboração e sugestões na redação deste trabalho.

Ao médico veterinário Dr. Fuad Naufel "in memorian", pelo incentivo investigação da influenza eqüina.

MANCINI, D.A.P.; GERALDES, E.A.; PINTO, J.R. Seroconversion in horses vaccinated with inactivated equine influenza vaccines. Braz J. vet. Res. anim. Sci., Såo Paulo, v.28, n.2, p.171-7, 1991 .

SUMMARY: The immonogenicity of the bivalent equine influenza vaccines (types $A / E q_{1}$ and $A / E q_{2}$ ) plain, or adjuvanted with aluminun hydroxide, produced at the Instituto Butantan, São Paulo, Brazil, was evaluated on horses sera taken before and after immunization by haemagglutination-inhibition (HI) and single radial haemolysis (SRH) tests. Seroconversion curves were established through weekly evaluations demonstrating good immunogenicity of both vaccines. Better humoral antibody titers were obtained with adjuvanted vaccine compared with the plain one, as showed by both methods used.

UNTERMS: Influenza of equine; Vaccine; Antibody formation

\section{REFERÊNCLAS BIRLIOGRÁFICAS}

01-BRYANS, J.T.; DOLL, E.R.; WILSON, J.C.; NCCOLLUM, W.M. Immunization for equine influenza. J. Amer. Vet Med.Ass., v.148, p.413-7, 1966.

02-CORREA, H.M.; CORREA, C.M.M. Enfermidodes infecciosas dos mamíferos domésticos. São Paulo, Varela, 1979. p.555-63: Enfermidades por Rickettsias e virus.

03-CUNHA, R.G. Isolamento de amostras de vírus influenza eqüina/A/Eq 2 no Estado da Guanabara. Rev. bras. Biol., v.30. p.491-8, 1970.

04-CUNHA, R.G.; PASSOS, H.S.; PAGANO, M.C.; SOUZA, D.M. Surto de gripe eqüina/produzida por vírus 
Ifitulo de anticorpos em cavalos imunizados com vacina contra influenza equina.

influenza $\mathrm{A} / \mathrm{Eq}_{2}$ no Estado do $R$ io de Janeiro, Brasil. Rev. bras. Med. vet., v.8, p.88-91, 1986.

05-CUNHA, R.G.; PASSOS, H.S.; RODRIGUES, A.F. Influência da via de inoculaçăo e do hidróxido de alumínio na resposta imunológica de covalos vacinados contra influenza equina. Arq. Insz Biol., Săo Paulo, v.40, p.357-68, 1973.

D6-CUNHA, R.G.; PASSOS, H.S.; VALLE, M.C.C. SUr to de gripe Eqüina produzida por vírus influenza $\mathrm{A} \mathrm{Eq}_{1}$ no Estado do Rio de Janeiro, Brasil. Rev. bras. Biol., v.38, p.549-54, 1978.

07-GOTO, H.; SHIMIZU, K.; TAYA, Y.; NODA, H.; TOKUNAGA, I. Antibody response of horses to equine influenza viruses during a postepizootic period in Japan. Canad J. comp. Med., v.46, p.2732,1982

08-KUCERA, C.J. The case for an adjuvanted equine influenza vaccine. J. Amer. Ver. Med. Ass., v.155, p.281-4, 1969.

09-LANGER, P.H. Equine influenza: development of a new combination vaccine. Ver. Med. small anim. Clin., v.61, p.662-8, 1966 .

10-MCQUeEN, J.L.; STEELE, J.H.; ROBINSON, R.Q. Equine influenza. Advanc. vet. Sci., v.12, p.285-336, 1968.

11-MANCINI, D.A.P.; GERALDES, E.A.; PINTO, J.R.; SOARES, M.A. Ocorrência de influenza equina na Fazenda São Joaquim, Săo Roque - SP, do Instituto Butantan. Rev. Fac. Med. Vet. Zootec Univ. S. Paulo., v.25, p.93-100, 1988.

12-DE MElo, J.L.; GUTENKUnSt, D.E.; BEILER, J.M.; PATON, I.M.; DE SANCTIS, A.M. The evaluation of an experimental bivalent equine influenza virus vaccine. J. Amer. Vel. Med. Ass., v.155, p.278-81, 1969.

13-MOORE, D.O. Developme-: and evolution of three vacc ines. Irish vet. J., v.40, p.105-7, 1986.
14-NAGAMINE, T.; ASAHARA, T.; HIGASHIHARA, M. Studies on a test vaccine for equine influenza virus. I. Production of a test vaccine. Kirasaso Arch exp. Med., v.48, P.53-67, 1975.

15-ORGANIZATION MONDIALE DE LA SANTE. COMite OMS d'experts de la standartisation biologique. Annexe 3. Normes revisées relatives au vaccin antigrippal (inactivé). Genève, 1978. p.161-78. (Série de Rapports Techniques, 638)

16-PEREIRA, H.G. Influenza antigenic spectrum. Progr med. Virol., v.11, p.46-79, 1969.

17-PIEGAS, N.S.; TAKIMOTO, S.; BARBOSA, H.H.G.: LACERDA, J.P.G.; GUARHIERI, R.; ISHIMARU, T. Isolemento de virus influenza de surto de gripe eqüina em Săo Paulo. In: CONGRESSO BRASILEIRO DE MEDICINA VETERINARIA, 15., Rio de Janeiro, 1976. Anais. P.122.

18-REISINGER, R.C. Corments on aqueous and adjuvanted equine influenza vaccines. J. Amer. Vet. Med Ass., $v .155,0.287-93,1969$.

19-SCHILD, G.C.; PEREIRA, M.S.; CHAKRAVERTY, P. single-radial-haemolysis: a new method for the assay of antibody to influenza haemagglut inin. Bull. Ind Hith Org., v.52, p.43-50, 1975.

20-SOVINOVA, O.; TUMOVA, B.; POUSKA, F.; NEMEC, J. Isolation of virus causing respiratory disease in horses. Acza virol., v.2, p.52-61, 1958.

21-TAKATSY, 6. The use of spiral loops in serological and virological micromethods. Acta microbiol. Acad. Sci Hung ., v.3, p.191, 1955.

22-WADDELL, L.G.H.; TEIGLAND, M.B.; SIGEL, M.M. A new influenza virus associated with equine respiratory disease. J. Amer. Vet Med. Ass., v.143, p.587-90, 1963 .

23-LOOD, J.M.; MUNFORD, J.; FOLKERS, C.; SCOTT, S.M.: SCKILD, G.C. Studies with inactivated equine influenza vaccine. J. Hyg., London. v.90, p.371. $84,1983$.

Recebido para publicaçāo em 23/11/90 Aprovado para publicaçāo em 10/10/91

Braz. J. vet. Res. anim. Sci., São Paulo, v.28, n.2, p.171-7, 1991 

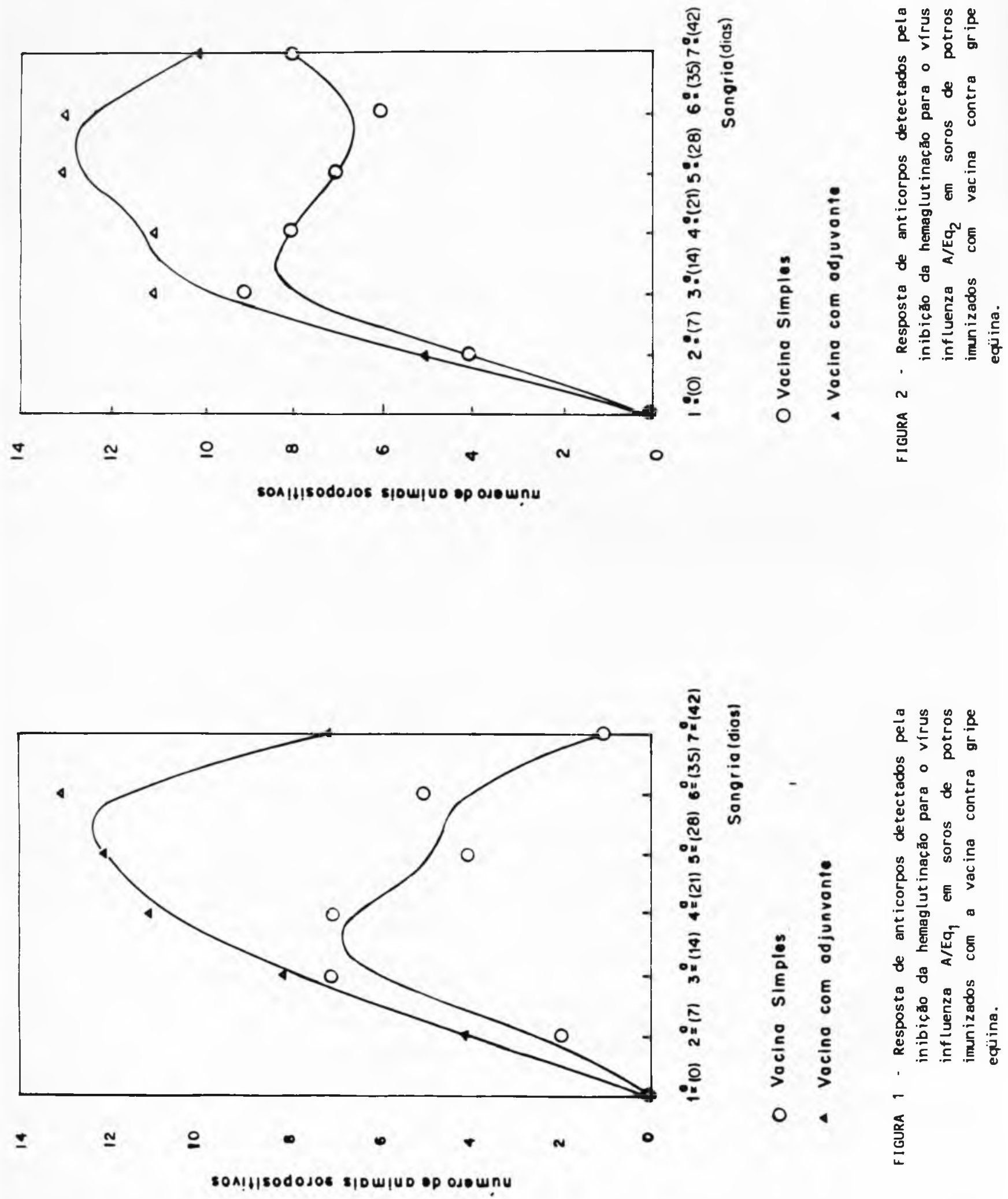

Braz. J. vel. Res. anim. Sci., São Paulo, v.28, n.2, p.171-7, 1991. 

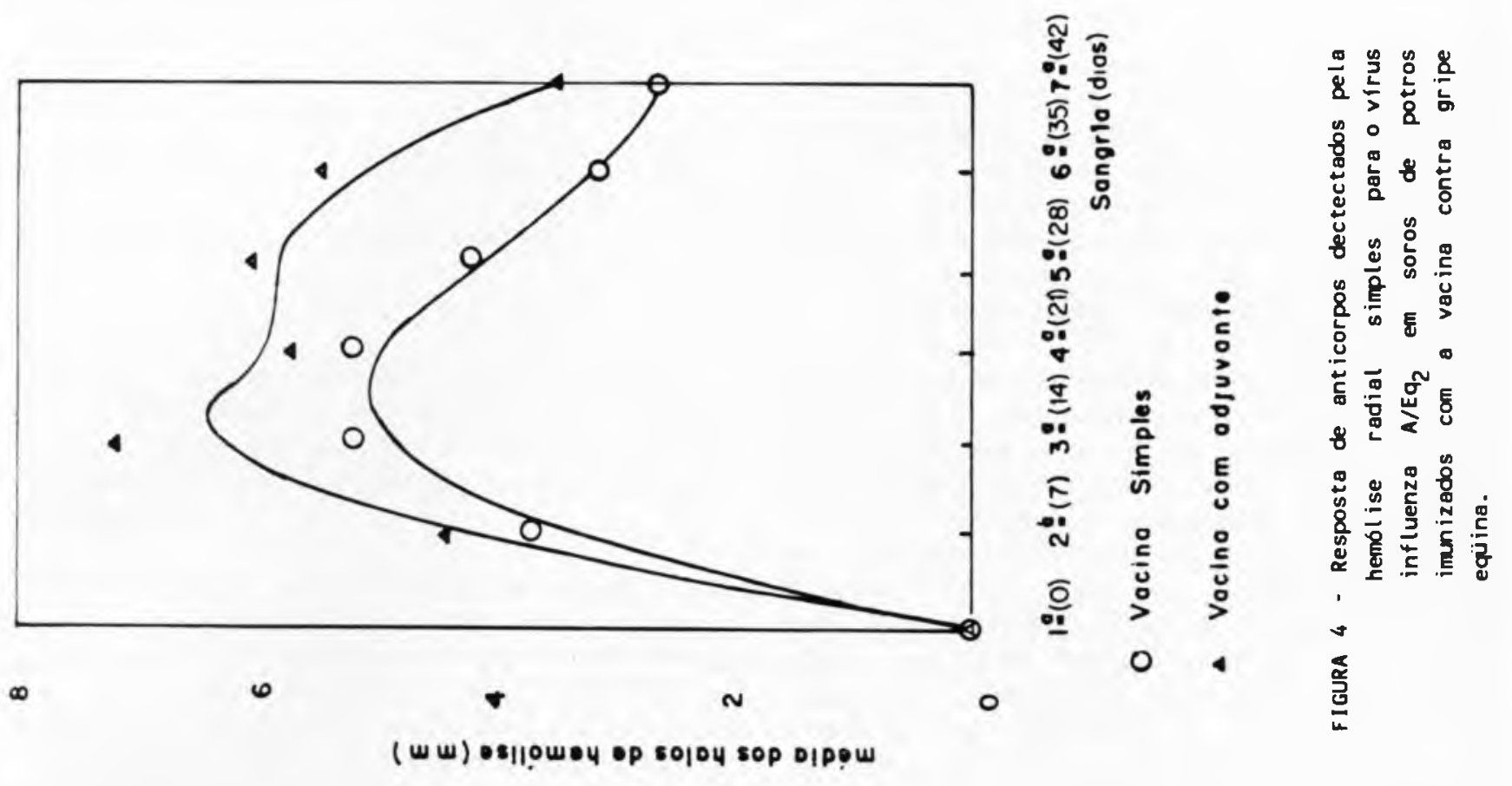

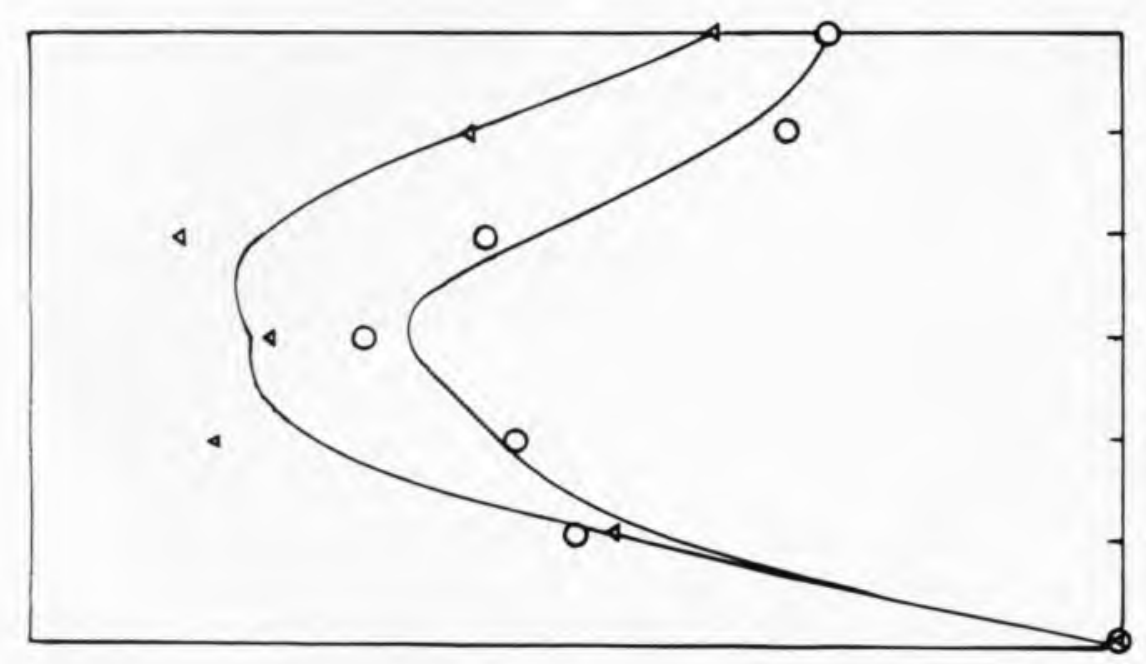

$\infty$
๑

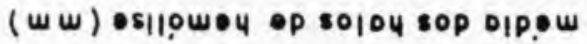

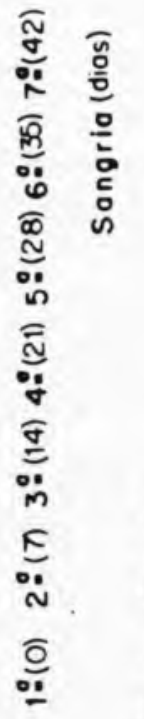

○

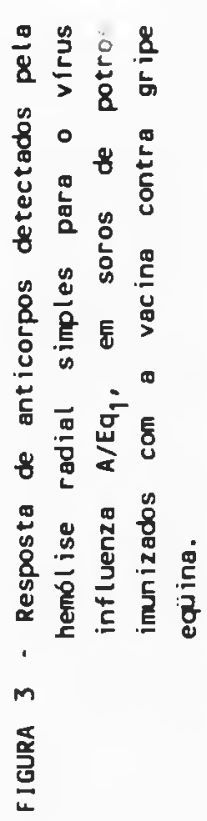

